Е. А. Жалсараева, М. А. Дугаржапова. Особенности региональной эколого ориентированной экономической политики в условиях пространственного развития

Научная статья

УДК 332

DOI 10.18101/2304-4446-2020-4-71-83

\title{
ОСОБЕННОСТИ РЕГИОНАЛЬНОЙ ЭКОЛОГО-ОРИЕНТИРОВАННОЙ ЭКОНОМИЧЕСКОЙ ПОЛИТИКИ В УСЛОВИЯХ ПРОСТРАНСТВЕННОГО РАЗВИТИЯ
}

\section{(C) Жалсараева Екатерина Александровна}

кандидат экономических наук, доцент, Восточно-Сибирский государственный университет технологий и управления Россия, 670013, г. Улан-Удэ, ул. Ключевская, 40в katya1e@yandex.ru

\section{(C) Дугаржапова Марина Абрамовна}

кандидат экономических наук, доцент, Бурятский государственный университет имени Доржи Банзарова Россия, 670000, г. Улан-Удэ, ул. Смолина, 24a uma79@mail.ru

Благодарность: статья подготовлена при финансовой поддержке Российского фонда фундаментальных исследований (проект №19-010-00906А «Развитие теоретических подходов и разработка механизмов эффективного взаимодействия субъектов Байкальского макрорегиона в условиях пространственного развития»)

Аннотация. В статье рассматриваются особенности экономической политики на региональном уровне с учетом экологических приоритетов в условиях пространственного развития. Все повышающиеся темпы развития региональных экономик приводят к увеличению антропогенной нагрузки на природные комплексы вплоть до их полного исчерпания. В связи с этим существует необходимость изменения стратегических планов развития на региональном уровне с учетов экологических приоритетов. Поэтому целью исследования является анализ экономической политики макрорегионов, их эколого-экономических проблем развития, выявление экологических приоритетов. Особенно важным это является в рамках реализации Стратегии пространственного развития, которая направлена на выравнивание межрегиональной экономической дифференциации. В статье на основе исследования существующих теорий раскрываются роль и значение экологического фактора при разработке основных положений экономической политики в пространственном развитии региона. Методология, используемая в исследовании, включает общенаучные методы и приемы: методы количественного и качественного анализа, научную абстракцию, анализ и синтез и сравнение. Основные результаты исследования - определены характеристики современных проблем эколого-экономических систем макрорегионов; проведен анализ учета экологического фактора в региональной политике в сравнении между тремя субъектами Байкальского региона, описаны эколого-экономические ограничения регионального развития на примере Байкальского региона, а также предложены рекомендации для совершенствования региональной экономической политики для сохранения уникальных природных комплексов озера Байкал и снижения антропогенного воздействия в условиях пространственного развития. 
Ключевые слова: пространственное развитие; территория; экологические ограничения; факторы пространственного развития; региональная экономика; приоритеты развития макрорегиона; региональная экономическая политика.

\section{Для цитирования}

Жалсараева Е. А., Дугаржапова М. А. Особенности региональной экологоориентированной экономической политики в условиях пространственного развития // Вестник Бурятского государственного университета. Экономика и менеджмент. 2020. № 4. C. 71-83.

\section{Введение и постановка проблемы}

Современное экономическое развитие характеризируется постоянной пространственной трансформацией связей и взаимодействий в материальных системах, то есть изменением как их состава и структуры, так и выполняемых ими функций. С точки зрения регионального экономического развития такая трансформация затрагивает и природные системы. В этих условиях стремление регионов к устойчивому экономическому развитию должно сопровождаться адекватной оценкой уровня экологического воздействия и разработкой механизмов сохранения уникальных природных комплексов. Данные положения имеют высокий уровень актуальности для регионального экономического развития при условии, что регионы представляются частью крупных образований - макрорегионов по положениям Стратегии пространственного развития РФ на период до 2025 г., утвержденной распоряжением правительства от 13 февраля 2019 г. №207-p. Основная цель пространственного развития Российской Федерации на период до 2025 г. - это обеспечение устойчивого и сбалансированного пространственного развития Российской Федерации, направленного на сокращение межрегиональных различий в уровне и качестве жизни населения; ускорение темпов экономического роста и технологического развития, а также обеспечение национальной безопасности страны. Для достижения указанной цели в Стратегии определено решение следующей задачи: обеспечение улучшения состояния окружающей среды, сохранение и восстановление биологического разнообразия Российской Федерации, культурных ландшафтов и сокращение негативных последствий от изменения климата ${ }^{1}$.

Решение данной задачи предполагает комплексное исследование состояния макрорегионов, а также выявление противоречий между сохранностью окружающей среды и развитием экономики.

\section{Методы исследования}

В качестве основы исследования в статье используются материалы разрабатываемого в настоящее время исследовательского проекта №19-010-00906А «Развитие теоретических подходов и разработка механизмов эффективного взаимодействия субъектов Байкальского макрорегиона в условиях пространственного развития», реализуемого при поддержке РФФИ. Был проведен анализ влияния экологических факторов на экономическое развитие макрорегионов. Иссле-

\footnotetext{
${ }^{1}$ Стратегия пространственного развития Российской Федерации на период до 2025 г., утв. Распоряжением Правительства РФ от 13.02.2019 г. №207-р.
} 
Е. А. Жалсараева, М. А. Дугаржапова. Особенности региональной эколого ориентированной экономической политики в условиях пространственного развития

дование проводилось с использованием общенаучных методов и приемов: научная абстракция, анализ и синтез и сравнение.

\section{Обзор ранее выполненных исследований}

Рассмотрение теоретической базы для обозначенных выше задач возможно на основе уже существующих учений, теорий и концепций, посвященных изучению пространственных аспектов развития экономических систем макрорегионов. Пространственное развитие территории рассматривается в трудах ученыхрегионоведов достаточно давно. Зарубежные авторы рассматривали особенности экономического развития регионов (Ф. Перру, Т. Хегерстрандт, П. Потье, Х. Ричардсон, П. Кругман) $[10,12]$, ими были заложены концептуальные основы (Карл Гуннар Мюрдаль) [9] и предложены различные подходы (Пьер Поттье, Джон Фридманн) $[12,8]$. Среди отечественных авторов необходимо отметить таких российских исследователей, как А. Г. Гранберг [2], С. В. Княгинин, Ю. Перелыгин, С. А. Суспицын [4], П. А. Минакир [3], В. Л. Глазычев [1, 2], И. Т. Насретдинов, В. И. Суслов, А. И. Татаркин и др. В их трудах были рассмотрены основы функционирования пространственной экономики. Развернутый анализ теоретической базы по проблемам пространственного развития в рамках проекта был представлен в коллективной научной статье «Актуальные вопросы регионального укрупнения в условиях пространственного развития», опубликованной в 2019г. По нашему мнению, эти исследования зарубежных и отечественных экономистов по вопросам пространственного развития территорий как экономического пространства наглядно подтверждают многообразие существующих подходов к проблемам реализации пространственного развития $[5,6]$.

Вопрос о создании и реализации эффективных эколого-экономических механизмов в условиях пространственного развития является актуальным для многих субъектов Российской Федерации. По нашему мнению, его содержание необходимо рассматривать комплексно, учитывая все факторы, определяющие региональный воспроизводственный процесс. Оценка состояния экономики региона в таком разрезе может быть представлена через исследование следующих аспектов экономического развития региона:

Bo-nервыx, исходя из территориальных условий существования, в том числе природных, географических, политических и др. Территориальные условия развития экономики любого региона, как правило, представляют собой совокупность трех основных компонентов: географического, природно-ресурсного и экономико-политического. Байкальский регион, включающий территорию Республики Бурятия, Иркутской области и Забайкальского края, характеризуется следующим образом.

Республика Бурятия представляет собой развивающийся регион площадью 351,3 тыс. км ${ }^{2}$ (2,1\% площади Российской Федерации) с огромным ресурсным, природным, туристско-рекреационным потенциалом. Географически республика расположена в южной части Восточной Сибири, восточнее озера Байкал, граничит с Республикой Тыва, с Иркутской областью, Забайкальским краем и с Монголией. Для территории республики характерен резко континентальный климат с ярко выраженными сезонами года. На территории располагается более 700 месторождений полезных ископаемых, в том числе более 300 месторождений золо- 
та, 13 - урана, 10 - бурого и 4 - каменного угля, 8 - плавикового шпата, 7 вольфрама, 4 - полиметаллов, 3-молибдена и бериллия, 1 - олова и алюминия, 2 - асбеста и др. В составе полезных ископаемых Республики Бурятия около двух третей приходится на топливно-энергетические ресурсы, благородные, цветные и редкие металлы. Земельный фонд составляет 35,1 млн га., в том числе каштановые, серые лесные и черноземные почвы, занимающие $56,4 \%$ площади всех сельскохозяйственных угодий и 76,5\% площади пахотных земель. Также к числу природных ресурсов относятся и лесные покровы республики, общая площадь которых составляет 27,0 млн га ${ }^{1}$.

Иркутская область является более экономически развитым по сравнению с другими субъектами, расположена в пределах Среднесибирского плоскогорья и захватывает бассейны рек Ангары, Лены и Нижней Тунгуски, занимая по площади 767,9 тыс. км ${ }^{2}$ (4,6\% российской территории). По уровню ресурсного потенциала Иркутская область - лидер среди субъектов Российской Федерации, имеет самую высокую лесистость (78\%), обусловленную наличием здесь порядка $11 \%$ общероссийских запасов древесины. По характеристике природного потенциала область богата месторождениями золота, редких металлов, легкообогатимых железных руд, слюды, магнезита, талька, калийной и поваренной соли, цветных и поделочных камней. Кроме этого, область располагает разнообразными видами собственных топливно-энергетических ресурсов - более 7\% общероссийских запасов угля, столько же нефти и горючего газа, в частности, благодаря наличию Ковыктинского газоконденсатного месторождения, Сухоложского месторождения рудного золота и др. ${ }^{2}$

Забайкальский край - регион крайнего юго-востока Сибири, включает в себя территорию Читинской области и Агинского Бурятского округа с площадью 431,9 тыс. км ${ }^{2}$ и граничит с Китаем и Монголией (показатель протяженности государственной границы с этими странами составляет 1926,8 км). Характеризуя промышленный потенциал края, необходимо отметить наличие станкостроительного и машиностроительного заводов в г. Чита, Дарасунского завода горного оборудования, Оловяннинского завода подъемно-транспортного оборудования, Сретенского судостроительного завода и др., серьезный вклад в экономику региона осуществляет топливно-энергетический комплекс, который включает в себя тепловые электростанции, работающие на угле (мощность 1366 тыс. кВт) и угольные разрезы (производительностью порядка 18,5 млн т в год). Имеются в Забайкальском крае и крупнейшие ресурсы сельскохозяйственных угодий (7652 тыс. га общей площади, в т. ч. 4652 тыс. га сенокосов и пастбищ, 505 тыс. га пашни), пригодных для ведения экономически эффективных видов агропроизводства. Кроме этого, необходимо отметить и наличие естественных кормовых угодий (36,1 \% угодий Восточной Сибири), что дает возможность развивать животноводство и овцеводство. Территория края является транзитной для маги-

\footnotetext{
1 Главное о регионе [Электронный ресурс]. URL: http://orv.gov.ru/Regions/Details/ 71 ? cat $=28$ (дата обращения: 22.07.2020).

${ }^{2}$ Иркутская область. [Электронный ресурс]. URL: http://sfo.gov.ru/okrug/IRK/ (дата обращения: 22.07.2020).
} 
Е. А. Жалсараева, М. А. Дугаржапова. Особенности региональной эколого ориентированной экономической политики в условиях пространственного развития

стрального железнодорожного транспорта. Забайкальская железная дорога расположена на территории Забайкальского края и Амурской области ${ }^{1}$.

$\mathrm{B}$ целом стратегический экономико-политический потенциал Байкальского региона составляют не только природные ресурсы, но особенность транспортного расположения: по территории трех субъектов проходят две федеральные железнодорожные линии - Транссибирская и Байкало-Амурская, а также три федеральные автомобильные трассы, а приграничные районы дают возможность для установления взаимовыгодных отношений и являются связующим транспортно-коммуникационным мостом России с Монголией, Китаем и другими странами Азиатско-Тихоокеанского региона. При этом большинство крупных уникальных месторождений полезных ископаемых расположены в радиусе до 200 км от ближайших железнодорожных линий Восточно-Сибирской железной дороги и Байкало-Амурской магистрали.

Связующим звеном экономик трех субъектов является озеро Байкал - природный резервуар пятой части мировых запасов пресной воды. Озеро Байкал и окружающую его территорию населяют 2500 различных видов животных и рыб, из которых 250 эндемичны. 60,0 \% береговой линии озера Байкал приходится на Республику Бурятия. Наличие этого уникального объекта природного наследия определяет необходимость использования в Байкальском регионе специальных режимов хозяйствования, определяющих экологическую нагрузку, связанную с сохранением уникальной экологической системы озера.

Bo-вторых, через исследование качества нормативно-правовой базы регионального развития, степени достаточности и проработанности нормативноправовых актов (табл. 1).

Таблица 1

Характеристика нормативно-правовой базы экологического регулирования субъектов Байкальского региона

Федеральный уровень

1. Федеральный закон РФ «Об охране озера Байкал» от 01.05.1999 г. № 94-Ф3.

2. Федеральный закон РФ «Об охране окружающей среды» от 10.01.2002 г. № 7-Ф3.

3. Федеральный закон от 04.05.1999 № 96-Ф3 «Об охране атмосферного воздуха».

4. Федеральный закон РФ от 21.02.1992 № 2395-1 «О недрах».

5. Федеральный закон от 14.03.1995 № 33-Ф3 «Об особо охраняемых природных территорияX».

6. Федеральный закон от 23.11.1995 № 174-Ф3 «Об экологической экспертизе».

7. Федеральный закон РФ «Об особо охраняемых природных территориях» от 14.03.1995 г. № 33-Ф3.

8. Федеральный закон РФ «О территориях традиционного природопользования коренных малочисленных народов Севера, Сибири и Дальнего Востока Российской Федерации» от 07.05.2001 г. № 49-Ф3.

9. Федеральный закон РФ «Об основах туристской деятельности в Российской Федерации» от 24.11.1996 г. № 132-Ф3.

\footnotetext{
1 Экономическое и географическое положение Забайкальского края в РФ [Электронный pecypc]. URL: https://promvest.info/ru/regionalnyiy-potentsial/ekonomicheskoe-igeograficheskoe-polojenie-zabaykalskogo-kraya-v-rossiyskoy-federatsii/ (дата обращения: 22.07.2020).
} 
10. Постановление Правительства РФ от 06.09.2000 г. № 661 «Об экологическом зонировании Байкальской природной территории и информировании населения о границах Байкальской природной территории, ее экологических зон и об особенностях режима экологических зон» 11. Постановление Правительства РФ от 03.02.2007 г. № 72 «О создании на территории Слюдянского района Иркутской области особой экономической зоны туристско-рекреационного типа»

12. Постановление Правительства РФ от 03.02.2007 г. № 68 «О создании на территории муниципального образования «Прибайкальский район» Республики Бурятия особой экономической зоны туристско-рекреационного типа»;

13. Постановление Правительства РФ от 30.08.2001 г. № 643 «Об утверждении перечня видов деятельности, запрещенных в центральной экологической зоне Байкальской природной территории»

Региональный уровень - Республика Бурятия

1. Закон Республики Бурятия от 25.11.2005 № 1348-III «Об охране окружающей среды в Республике Бурятия»;

2. Закон Республики Бурятия от 29.12.2005 № 1438-III «Об особо охраняемых природных территориях Республики Бурятия»;

3. Постановление Правительства РБ от 21.12.2006 № 408 «О Порядке охраны особо охраняемых природных территорий Республики Бурятия»;

4. Постановление Правительства РБ от 30.09.2011 № 504 «Об утверждении условий раздельного сбора отходов на территории Республики Бурятия»;

5. Распоряжение Правительства РБ от 05.06.2001 № 571-р «О согласовании положений о рекреационных местностях местного значения “Лемасово” и “Байкальский прибой - Култушная" Кабанского района»

Региональный уровень - Иркутская область

1. Закон Иркутской области от 10.11.2011 № 107-оз «Об областной государственной поддержке деятельности, направленной на сохранение и улучшение состояния уникальной экологической системы озера Байкал»;

2. Закон Иркутской области от 11.06.2008 № 23-оз «Об отдельных вопросах охраны окружающей среды в Иркутской области»;

3. Закон Иркутской области от 19.06.2008 № 27-оз «Об особо охраняемых природных территориях и иных особо охраняемых территориях в Иркутской области»;

4. Закон Иркутской области от 24.06.2008 № 30-оз «О Красной книге Иркутской области»;

5. Закон Иркутской области от 11.06.2008 № 23-оз «Об отдельных вопросах охраны окружающей среды в Иркутской области»;

6. Положение о порядке организации работы по информационной и организационной поддержке деятельности, направленной на сохранение и улучшение состояния уникальной экологической системы озера Байкал, утвержденное постановлением Правительства Иркутской области от 30 марта 2012 года № 124-пп

Региональный уровень - Забайкальский край

1. Постановление Правительства Забайкальского края от 09.09.2014 № 535 (ред. от 29.08.2016) «Об утверждении Порядка осуществления регионального государственного экологического надзора»;

2. Распоряжение Администрации Читинской области от 20.02.2007 № 107-А/р «О проведении акции «День Байкала - 2007»;

3. Закон Забайкальского края от 09.03.2010 г. № 338-33К «Об особо охраняемых природных территориях в Забайкальском крае»;

4. Концепция развития системы ООПТ регионального значения в Забайкальском крае на период до 2030 года (утверждена постановлением Правительства Забайкальского края от 01.03.2016 г. № 89)

Из данных таблицы 1 видно, что на федеральном уровне законодательство обеспечивает исполнение основного момента по сохранению природных объек- 
Е. А. Жалсараева, М. А. Дугаржапова. Особенности региональной эколого ориентированной экономической политики в условиях пространственного развития

тов и обеспечению рационального использования природных ресурсов. Вместе с тем база нормативных актов в регионах не такая обширная и часто носит формальный характер. Исполнение основных законодательных актов реализуется через такой инструмент экономической политики, как государственные программы. Их количество обусловлено спецификой ресурсного потенциала региона. Так в настоящее время в Республике Бурятия реализуется порядка 25 государственных программ различного направления согласно распоряжению Правительства Республики Бурятия от 30 ноября 2011 г. № 852-р «Об утверждении Перечня государственных программ Республики Бурятия», в Иркутской области 21 по постановлению Правительства Иркутской области от 5 октября 2018 г. № 726-пп «Перечень государственных программ Иркутской области», в Забайкальском крае - 31 на основании распоряжения Правительства Забайкальского края от 15 мая 2012 г. № 223-р «Об утверждении перечня государственных программ Забайкальского края», однако реализация мероприятий данных программ часто не актуализирована про времени и их финансирование имеет недостаточный объем.

Сама по себе нормативная база имеет существенные пробелы, в том числе устаревание, несоответствие между уровнями разработки и применения, а также в ряде случаев противоречивость. Показать неэффективность законодательства можно на примере законодательных норм в отношении функционирования особо охраняемых природных территорий (ООПТ) в Тункинском районе Республики Бурятия. Границы административного района, муниципального образования практически полностью совпадают с границами Тункинского национального парка, что не позволяет применить к деятельности экономических субъектов в рамках Тункинского района законы без учета особого статуса территории, однако и нормативная база по функционированию ООПТ в этих условиях не работает. Также в качестве примера можно привести тот факт, что правовыми актами, вводившими понятия «Байкальская природная территория», «экологические зоны» и другие термины, включая понятийный аппарат механизмов запрещающих любую хозяйственную деятельность, по сути не был определен и закреплен особый статус для экономических субъектов, располагающихся на данной территории. По современному состоянию экономики района можно судить об отсутствии возможностей развития каких-либо сфер экономики, кроме туристической, которая сильно зависит от сезона из-за климатических особенностей и, естественно, не дает прогнозировать постоянный приток финансовых ресурсов ${ }^{1}$.

Кроме этого, практически нет межсубъектных законодательных актов, через которые можно было бы осуществлять взаимодействие и взаиморегулирование направлений эколого-экономической политики в Байкальском регионе в целом. Исключением можно назвать лишь создание в 2007 г. межведомственной комиссии по вопросам охраны озера Байкал, (Приказ Минприроды РФ от 25.04.2007 г. № 114).

$B$ третьих, через оценку направлений региональной политики. Региональная экономическая политика, как правило, вырабатывается на основе особенностей

1 Особо охраняемые природные территории [Электронный ресурc]. URL: https://minprir.75.ru/deyatel-nost/osobo-ohranyaemye-prirodnye-territorii (дата обращения: 22.07.2020). 
развития региона, его природно-ресурсного потенциала, географического положения и прочих территориальных, социальных особенностей. В этом смысле политика, реализуемая в Байкальском регионе в условиях пространственного развития, также разработана с учетом факторов внутренних и внешних.

Стратегические направления региональной политики закрепляются в различных документах, носящих как концептуальный, так и прикладной характер. Так, в 2009 г. была принята Стратегия социально-экономического развития Дальнего Востока и Байкальского региона на период до 2025 г., в рамках которой на основе анализа вызовов и угроз, были выявлены преимущества для развития Дальнего Востока и Байкальского региона. Кроме этого на уровне субъектов были приняты соответствующие документы, отражающие направления развития экономики на перспективу. Сравнительный анализ основных направлений социальноэкономического развития субъектов Байкальского региона представлен в табл. 2.

Таблица 2

Направления социально-экономического развития субъектов Байкальского региона

\begin{tabular}{|c|c|c|}
\hline Республика Бурятия & Иркутская область & Забайкальский край \\
\hline \multicolumn{3}{|c|}{ Нормативный документ } \\
\hline $\begin{array}{l}\text { Закон Республики Бурятия от } \\
18 \text { марта } 2019 \text { г. № 360-VI «О } \\
\text { Стратегии социально- } \\
\text { экономического развития } \\
\text { Республики Бурятия на пери- } \\
\text { од до } 2035 \text { г.»; } \\
\text { Закон Республики Бурятия от } \\
4 \text { марта } 2016 \text { г. № 1639-V «О } \\
\text { стратегическом планировании } \\
\text { в Республике Бурятия» }\end{array}$ & $\begin{array}{l}\text { Постановление Законодатель- } \\
\text { ного собрания Иркутской об- } \\
\text { ласти от 15.02.2017 г. 47/42-3С } \\
\text { о проекте закона Иркутской } \\
\text { области «Об утверждении } \\
\text { закона о стратегии социально- } \\
\text { экономического развития на } \\
\text { период } 2030 \text { г.» }\end{array}$ & $\begin{array}{l}\text { Постановление Правительства } \\
\text { Забайкальского края «Об } \\
\text { утверждении Стратегии соци- } \\
\text { ально-экономического разви- } \\
\text { тия Забайкальского края на } \\
\text { период до } 2030 \text { г.» }\end{array}$ \\
\hline \multicolumn{3}{|c|}{ Направления экономического развития региона } \\
\hline \multicolumn{3}{|c|}{ Республика Бурятия } \\
\hline $\begin{array}{l}\text { 1. Развитие человеческого поте } \\
\text { сферы). } \\
\text { 2. Развитие промышленного по } \\
\text { экономики республики, использ } \\
\text { 3. Развитие локальной экономи } \\
\text { начальном этапе выходов на ме } \\
\text { печить занятость и индивидуаль } \\
\text { 4. Коммерциализация инноваци } \\
\text { ное предпринимательство). } \\
\text { 5. Развитие АПК как специфик } \\
\text { импортозамещения, помощь се } \\
\text { 6. Развитие сферы услуг (создани } \\
\text { 7. Развитие инфраструктурного } \\
\text { онной инфраструктуры через ре }\end{array}$ & $\begin{array}{l}\text { циала (повышение уровня образ } \\
\text { енциала (эколого-ориентирован } \\
\text { вание ресурсов с учетом дальней } \\
\text { ки (использование местных ресу } \\
\text { стные рынки, в дальнейшем на р } \\
\text { ый подход). } \\
\text { онных разработок научно-образо } \\
\text { ции экономики республики (реш } \\
\text { ьским бизнес-структурам, создани } \\
\text { в первую очередь комфортной сре } \\
\text { аркаса, транспортных коридоров } \\
\text { ализации национальных проектов }\end{array}$ & $\begin{array}{l}\text { ванности, развитие социальной } \\
\text { ые бизнес-структуры как каркас } \\
\text { шего увеличения их объемов). } \\
\text { сов всех типов с созданием на } \\
\text { гиональные, что позволит обес- } \\
\text { ательной системы (инновацион- } \\
\text { ение продовольственных задач } \\
\text { е органической продукции). } \\
\text { ы для туристического потока). } \\
\text { энергетической, коммуникаци- } \\
\text { в данных областях }\end{array}$ \\
\hline
\end{tabular}


Е. А. Жалсараева, М. А. Дугаржапова. Особенности региональной эколого ориентированной экономической политики в условиях пространственного развития

Иркутская область

Приоритеты социально-экономической политики региона определяются с целью максимальной концентрации имеющихся ресурсов в перспективных направлениях, позволяющих добиться достижения основной цели стратегии. С учетом анализа социально-экономического развития региона выбраны 4 стратегических приоритета:

Приоритет 1. «Накопление и развитие человеческого капитала»: обеспечение опережающего развития человеческого капитала с одновременным созданием условий для закрепления людей на территории Иркутской области, в том числе повышение уровня образования, доступности медицинских услуг, повышение уровня культуры и решение задач молодежной политики.

Приоритет 2. «Создание комфортного пространства для жизни»: повышение доступности жилья для населения Иркутской области и увеличение объема строительства жилья, кардинальное повышение комфортности городской среды; обеспечение непрерывного функционирования дорожного хозяйства, повышение доступности транспортных услуг, укрепление продовольственной безопасности, повышение уровня самообеспечения области основными видами сельскохозяйственной и пищевой продукции за счет всестороннего развития агропромышленного комплекса; развитие сельских территорий.

Приоритет 3. «Сохранение уникальной экосистемы региона»: приоритетами экологической политики для региона являются сокращение объемов сбрасываемых в водные источники неочищенных сточных вод и выбросов вредных веществ в атмосферу, снижение уровня загрязнения атмосферного воздуха, эффективное обращение с отходами производства и потребления, включая ликвидацию свалок, обеспечение устойчивого развития экологически значимых природных комплексов, сохранение биологического разнообразия животного и растительного мира (с особым акцентом на сохранение животных, растений и других организмов, занесенных в Красную книгу Иркутской области), в том числе посредством создания новых особо охраняемых природных территорий регионального значения.

Приоритет 4. «Экономический рост и эффективное управление»: повышение инвестиционной привлекательности области; развитие сферы малого и среднего предпринимательства как одного из факторов инновационного развития, улучшение отраслевой структуры экономики, увеличение занятости населения и снижения безработицы

Забайкальский край

Направления экономического развития зависят от специфики региона, исходя от сценария развития формируются две альтернативы развития Забайкальского края: по инерционному сценарию и сценарию сбалансированного развития.

Инерционный сценарий: основные виды деятельности в крае уже структурировались и закрепились, то есть сохранится сырьевая специализация хозяйственного комплекса края и транспортнотранзитные функции в пределах существующих участков федеральных автомагистралей и железной дороги, при этом будет наблюдаться высокая зависимость от бюджетных трансфертов.

Сценарий сбалансированного развития предусматривает формирование пространства развития, то есть развитие региона зависит от развития его человеческого потенциала (развитие культуры, образования, здравоохранения, физической культуры и спорта); предусматривается опережающее развитие края за счет структурных преобразований в составе отраслей специализации региональной экономики, связанных с внедрением и переходом к новым производственным технологиям в горно-добывающей промышленности, обрабатывающих производствах, строительстве, сельском хозяйстве, лесозаготовках, использование современного оборудования. Наряду с традиционными отраслями-лидерами (горнорудная промышленность, транспорт и др.) предполагается приоритетное развитие ряда новых и ранее не получивших должного наполнения секторов экономики - транспортной логистики, производств, связанных с углубленной переработкой ресурсов, экспорто-ориентированного сельхозпроизводства, въездного туризма. Основным способом территориально-пространственной организации производства станет создание и развитие парковых и кластерных образований, что позволит сохранить высокие темпы роста привлечения инвестиций во все сектора хозяйства региона, включая частные капиталовложения в социальную среду. Предполагается усиление экономической роли трансграничного статуса региона, увеличение 
внешнеторгового оборота и постепенное изменение его товарной структуры в сторону повышения технологичности поставляемой отечественной продукции и товаров

Экологические приоритеты развития

Развитие туристско- Применение природосберегарекреационного направления; ющих технологий, производсоздание условий для рацио- ство экологически чистой пронального использования при- дукции Развитие экологически ориентированных производств, эколого-ориентированный подход к разработке природных родных ресурсов

Главная стратегическая цель каждого из субъектов — достижение устойчивого экономического развития. В условиях же изменения климата и усиления глобализации экономическое развитие в долгосрочном формате возможно лишь с учетом экологического фактора. Одним из важнейших моментов, упомянутых в стратегии, является необходимость учитывать риски и ограничения экономического роста, связанные с опасностью загрязнения окружающей среды со стороны ресурсных секторов и разрушения природных экосистем в зонах повышенной концентрации экономической активности, а также с изменением климата на территории Дальнего Востока и Байкальского региона.

Вместе с тем, учитывая специфику каждого из субъектов, входящих в состав Байкальского региона, к числу важнейших моментов для региональной экономической политики относится экологический приоритет, выраженный через развитие туристско-рекреационного направления. Для Иркутской области таким направлением становится экологически ориентированное развитие промышленности, то есть использование промышленного потенциала с учетом принципов рационального природопользования. Для Забайкальского края в качестве приоритетного направления рассматривается экологичная разработка месторождений природных ресурсов и их дальнейшего использования.

Также для всех трех субъектов немаловажную роль играет наличие на их территории большого количества особо охраняемых природных территорий (ООПТ) федерального, регионального и местного значения.

Система ООПТ Республики Бурятия достаточно обширна. На сегодня она включает:

1) объекты федерального значения : биосферные -2 и природные -1 заповедники, национальные парки (Тункинский и Забайкальский), федеральные природные заказники;

2) региональные объекты : заказники - 13 , природный парк -1 , рекреационная местность -1 и памятники природы $-62^{1}$.

На территории Иркутской области располагаются пять особо охраняемых природных территорий федерального значения (площадь 1 844, 874 тыс. га, из них на Байкальской природной территории расположено 4 ООПТ) общей площадью 1 126,347 тыс. га. Региональные объекты - это 13 государственных при-

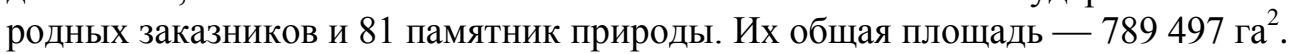

1 Особо охраняемые природные территории [Электронный ресурс]. URL: https://irkobl.ru/sites/ecology/working/ohrana/oopt/ (дата обращения: 22.07.2020).

${ }^{2}$ Там же. 
Е. А. Жалсараева, М. А. Дугаржапова. Особенности региональной эколого ориентированной экономической политики в условиях пространственного развития

На территории Забайкальского края существует 94 ООПТ разных категорий, из них 8 - федерального значения и 86 - регионального: государственный природный биосферный заповедник «Даурский», Сохондинский государственный природный биосферный заповедник, национальные парки «Алханай», «Чикой» и «Кодар», а также заказники федерального значения «Цасучейский бор» и «Долина дзерена» и памятники природы составляют по площади 1 836,131 тыс. га, или $4,25 \%$ территории края ${ }^{1}$.

Система ООПТ, столь многочисленно представленная в Байкальском регионе, также нуждается в постоянном мониторинге и охране. По своему назначению такие участки изымаются из хозяйственного оборота, поэтому ежегодно встает вопрос конфликта между экономическим и экологическими целями развития.

\section{Результаты исследования}

Ориентируясь на современное состояние регионального развития, можно определить ряд ключевых проблем функционирования Байкальского региона, решение которых должно найти отражение в региональной экономической политике:

1. Несовершенство нормативно-правовой базы, существующей в настоящее время. В частности, необходима разработка единого набора нормативов, методик и рекомендаций, а также экологического инвентаризационного стандарта для хозяйствующих субъектов региона, определяющих уровень воздействия, нормы и лимиты. Этот набор должен быть равнозначно применим на всей территории Байкальского региона.

2. Существует объективная необходимость создания единой автоматизированной базы данных по охране окружающей среды, которая будет отражать как актуальное состояние, так и представлять инструмент для постоянного мониторинга в перспективе.

3. Нет выраженного взаимодействия на уровне региональных властных структур по разработке единого плана развития Байкальского региона.

Эти и другие проблемы должны найти отражение при реализации региональной экономической политики всех трёх субъектов.

Для решения проблем региона должна быть сформирована комплексная межсубъектная экологическая программа. Для ее формирования необходимо провести экологический аудит всех направлений экономической политики, в том числе оценку комплексных схем и региональных целевых программ охраны и использования природных ресурсов на основе системы мониторинга состояния и использования природных ресурсов применением ГИС-технологий,

Уже на основе оценки состояния должен быть разработан перечень мероприятий и инвестиционных проектов по охране и использованию отдельных видов природных ресурсов, включая мероприятия по решению проблем трансграничного воздействия на окружающую среду и природные объекты

Такой подход обеспечит эффективный контроль за состоянием окружающей природной среды, даст возможность своевременно реагировать на ее изменения и в конечном итоге обеспечит формирование благоприятной для человека среды

1 Особо охраняемые природные территории [Электронный ресурc]. URL: https://minprir.75.ru/deyatel-nost/osobo-ohranyaemye-prirodnye-territorii (дата обращения: 22.07.2020). 
обитания, т. е. сохранение способности естественных экосистем региона эффективно выполнять биосферные функции по сохранению уникальности биотических компонентов окружающей среды озера Байкал, а также позволит развивать экономику без агрессивного влияния на природную среду.

К числу инструментов для создания такого механизма можно отнести экологическое зонирование территории (к нестоящему времени зонирование проведено, но нуждается в значительной корректировке), экологическое нормирование (нормы федерального значения предлагается дополнить с учетом особенностей и специфики региона), экологическую паспортизацию, экологический мониторинг, экологическую экспертизу, экологический контроль, экологический аудит и т. д.

\section{Выводы}

Таким образом, в завершении исследования можно сделать следующие выводы:

1. Экономическое развитие региона должно реализовываться на основании комплексной оценки его потенциала, на основе принципов рационального использования природных ресурсов.

2. Существует объективная необходимость совершенствования нормативноправовой базы для соблюдения экологических приоритетов при экономическом развитии.

3. Обоснована потребность в создании и последовательном применении механизмов такого развития.

В целом, оценивая экологические приоритеты для развития экономики Байкальского региона, можно сказать, что постановка проблем и задач сохранения природной среды является одним из важнейших элементов региональной экономической политики, но необходимо усовершенствование существующих механизмов и комплексный подход к их решению в условиях пространственного развития.

\section{Литература}

1. Глазычев В.Л. Город без границ. М.: Территория будущего, 2011. 398 c.

2. Гранберг А. Г. Основы региональной экономики: учебник. М.: ГУВШЭ, 2000. $495 \mathrm{c}$.

3. Минакир П. А. «Стратегия пространственного развития» в интерьере концепций пространственной организации экономики // Пространственная экономика. 2018. № 4. C. 8-6.

4. Суспицын С. А. Развитие методов измерения пространственных трансформаций экономики // Регион: экономика и социология. 2007. № 4. С. 3-18.

5. Жалсараева Е. А., Дугаржапова М. А., Маланов В. И., Шангина А. В. Пространственное развитие в условиях регионального укрупнения // Вестник Забайкальского государственного университета. 2019. Т. 25, № 7. С. 120-129.

6. Жалсараева Е. А., Дугаржапова М. А., Шангина А. В. Экологические ограничения пространственного развития в практике российских регионов//Вестник Российского экономического университета им. Г. В. Плеханова. 2019. № 6(108). С. 32-42.

7. Глазычев В. Л. Россия: территория пространственного развития [Электронный реcypc]. URL: http://www.glazychev.ru/projects/2004_prostrazv/2004_docladprostrazv.htm (дата обращения: 22.07.2020).

8. John Friedmann. Regional Development Policy: A Case Study of Venezuela. MIT Press. 1966. $279 \mathrm{p}$.

9. Myrdal G. Asian drama: An Inquiry into the Poverty of Nations. 1968. 705 c. 
Е. А. Жалсараева, М. А. Дугаржапова. Особенности региональной эколого ориентированной экономической политики в условиях пространственного развития

10. Perroux F. Economic space: theory and applications // Quarterly Journal of Economics. 1950. 64. P. 89-104.

11. Perroux F. Note sur la notion de pôle de croissance // Économie appliquée. 1955. Vol. 8. P. 307-320.

12. Pierre Pottier. Axes de communication et développement économique // Revue économique. 1963. T. 14. C. 58-132.

\section{FEATURES OF REGIONAL ENVIRONMENTALLY FRIENDLY ECONOMIC POLICY IN THE CONTEXT OF SPATIAL DEVELOPMENT}

Ekaterina A. Zhalsaraeva

Cand. Sci. (Econ.), A/Prof.,

East-Siberian State University of Technology and Management

40v Klyuchevskaya St., Ulan-Ude 670013, Russia

katya1e@yandex.ru

Marina A. Dugarzhapova

Cand. Sci. (Econ.), A/Prof.,

Dorzhi Banzarov Buryat State University

24a Smolina St., Ulan-Ude 670000, Russia

uma79@mail.ru

Abstract. The article considers the features of economic policy at the regional level, taking into account environmental priorities in the context of spatial development. The increasing rates of regional economies growth lead to an increase in the anthropogenic load on natural complexes, up to their complete exhaustion. In this regard, there is a need to change strategic development plans at the regional level with respect to environmental priorities. Therefore, the study analyzes the economic policy of macroregions, their environmental and economic development problems, and identifies environmental priorities. This is especially important in the context of implementing the Spatial Development Strategy, which is aimed at leveling interregional economic differentiation. Based on the study of existing theories, we have revealed the role and significance of the environmental factor in adopting the economic policy of spatial development in regions. The methodology used in the research includes general scientific methods and techniques: methods of quantitative and qualitative analysis, scientific abstraction, analysis and synthesis, and comparison. As a result of research, we have identified the key characteristics of modern ecological and economic problems in macroregions, analyzed and compared the environment friendliness of regional policy in the three subjects of the Baikal region, described the environmental and economic constraints of the regional development using the example of the Baikal region, and given recommendations for improving the regional economic policy with a view to preserve the unique natural complexes of Lake Baikal and reduce anthropogenic impact in the context of spatial development.

Keywords: spatial development; territory; environmental constraints; factors of spatial development; regional economy; priorities for the development of a macroregion; regional economic policy.

Статья поступила в редакцию 29.09.2020; одобрена после рецензирования 30.10.2020; принята к публикации 30.10.2020. 